\title{
VALIDASI BISNIS ARSITEKTUR MODEL MENGGUNAKAN METODE FORMAL (STUDI KASUS: MANUFAKTURING)
}

\author{
Syifa Annastasia ${ }^{1 *}$, Asti Amalia Nur Fajrilah ${ }^{1}$, Berlian Maulidya Izzati ${ }^{1}$ \\ ${ }^{1}$ Sistem Informasi, Universitas Telkom \\ email: *syifaannastasia@ student.telkomuniversity.ac.id
}

\begin{abstract}
Roeleven and Broer reveal that more than 66\% of EA programs do not live up to expectations due to a failure to demonstrate sufficient value for the business. Business architecture has an important role to help companies achieve the desired business values. An organization also depends on how well the information provided on each artifact especially in the architectural business phase. That way, failure in business modeling can also have an impact on EA implementationw. Modeling artifacts in a good architectural business phase can help to avoid mistakes from the start, because the quality of the business modeling model will have an impact on the quality of information system design. Therefore, it need to test the quality of the model on every artifact in the architectural business, because many business models are not always of high quality. To have a high quality EA, one of them is by identifying a conceptual quality framework approach. There are six principles that must be considered when assessing the quality of a company model, in this study using the quality of the business architecture validity model with six attributes using the formal Petri net method.
\end{abstract}

Keywords: Enterprise Architecture; Business Architecture; Business Process; Validity, Attribute Quality

\begin{abstract}
Abstrak: Roeleven dan Broer mengungkapkan bahwa lebih dari 66\% program EA tidak memenuhi harapan karena kegagalan untuk menunjukkan nilai yang cukup untuk bisnis. Arsitektur bisnis memiliki peran penting untuk membantu perusahaan mencapai nilai bisnis yang diinginkan. Sebuah organisasi juga bergantung pada seberapa baiknya informasi yang diberikan pada setiap artefak terutama pada fase bisnis arsitektur. Dengan begitu kegagalan pemodelan bisnis juga dapat berdampak pada implementasi EA. Memodelkan artefak pada fase bisnis arsitektur yang baik dapat membantu untuk menghindari kesalahan sejak awal karena kualitas model pemodelan bisnis akan berdampak pada kualitas desain sistem informasi. Maka dari itu, kualitas dari pemodelan bisnis model telah diakui sebagai faktor penting untuk pemodelan sukses di perusahaan, serta perlunya untuk melakukan pengujian kualitas model pada setiap artefak pada bisnis arsitektur, karena banyak model bisnis yang tidak selalu berkualitas tinggi. Untuk memiliki EA yang berkualitas tinggi salah satunya dengan mengidentifikasi pendekatan kerangka kualitas konseptual. Terdapat enam prinsip yang harus dipertimbangkan ketika menilai kualitas model perusahaan, dalam kajian ini menggunakan kualitas model validity arsitektur bisnis dengan enam atribut menggunakan metode formal Petri net.
\end{abstract}

Kata kunci: Arsitektur Perusahaan; Bisnis Arsitektur; Proses Bisnis; Validitas; Kualitas Atribut 
DOI: https://doi.org/10.33330/jurteksi.v7i2.1009

Available online at http://jurnal.stmikroyal.ac.id/index.php/jurteksi

\section{PENDAHULUAN}

Enterprise Architecture (EA) merupakan pandangan tingkat tinggi terhadap strategi bisnis dan sistem teknologi informasi perusahaan yang diinginkan masa depan [1]. Bisa dikatakan bahwa EA sangat berperan penting bagi perusahaan, karena memiliki fungsi menerjemahkan strategi, kapabilitas, dan tujuan kedalam sistem agar dapat mewujudkan goals perusahaan. EA juga menerjemahkan visi dan misi organisasi menjadi kenyataan operasional dan memanfaatkan teknologi saat ini untuk meningkatkan sistem layanan sektor publik [2]. Banyak organisasi menghadapi masalah dalam mengimplementasikan fungsi EA yang efektif karena struktur bisnis dan teknologi informasi tidak fleksibel dan rumit. Belajar dari Roeleven dan Broer mengungkapkan bahwa lebih dari $66 \%$ program EA di Belanda tidak memenuhi harapan, Gartner Group memperkirakan $40 \%$ dari semua program EA akan dihentikan karena kegagalan untuk menunjukkan nilai yang cukup untuk bisnis, permasalahan utama yang dihadapi dalam proses implementasi EA diantaranya yaitu (1) kompleksitas kerangka kerja dan metodelogi EA yang ada, (2) kekakuan fungsionalitas bisnis di organisasi, (3) struktur teknologi informasi yang tidak teratur [2]. Banyak kerangka kerja arsitektur yang tersedia hanya fokus tentang solusi teknologi dan proses bisnis tapi tidak mengatasi tantangan pengembangan EA, implementasi, dan adopsi dalam organisasi. Selain itu, sebuah organisasi juga bergantung pada seberapa baiknya informasi yang diberikan pada setiap artefak yang di desain pada setiap fase terutama pada fase bisnis arsitektur. dengan begitu kegagalan pemodelan bisnis juga dapat berdampak pada implementasi EA karena akan berpotensi mengganggu jalannya aktivitas perusahaan [3]. Organisasi disarankan untuk membangun EA secara bertahap walaupun membutuhkan waktu banyak untuk memastikan EA yang dibangun dapat berkembang dengan baik, agar tidak menyebabkan kekurangan keselarasan antara kegiatan bisnis dan teknologi informasi.

Salah satu framework EA adalah The Open Group Architecture Framework (TOGAF). TOGAF digunakan dalam mengembangkan EA, terdapat empat domain arsitektur pada TOGAF diantaranya adalah (1) bisnis arsitektur, (2) data arsitektur, (3) aplikasi arsitektur, dan (4) teknologi arsitektur [4]. Arsitektur bisnis pada EA memiliki tanggung jawab besar untuk menangani semua sistem informasi dan aplikasi yang berjalan di perusahaan, ini menyoroti pentingnya penerapan arsitektur bisnis [5]. Memodelkan pemodelan bisnis yang baik dapat membantu untuk menghindari kesalahan sejak awal karena kualitas model bisnis akan berdampak pada kualitas desain sistem informasi. Maka dari itu, kualitas dari pemodelan bisnis telah diakui sebagai faktor penting untuk pemodelan yang sukses di perusahaan serta perlunya untuk melakukan pengujian kualitas pemodelan bisnis karena banyak model bisnis yang tidak selalu berkualitas tinggi [6]. Secara umum EA yang memiliki kualitas tinggi ialah yang sesuai dengan pesyaratan bisnis yang disepakati dan dipahami. Untuk memiliki EA berkualitas tinggi salah satunya dengan mengidentifikasi pendekatan kerangka kerja kualitas konseptual [7].

Kualitas skema konseptual dapat diuraikan pada tiga tingkatan yang berbeda yaitu (1) sintaksis, (2) semantik, 
dan (3) pragmatis [8]. Terdapat enam prinsip yang harus dipertimbangkan ketika menilai kualitas model perusahaan yaitu (1) principle of validity, (2) principle of relevance, (3) principle of clarity, (4) principle of economic efficiency, (5) principle of systematic model construction, dan (6) principle of comparison [7].

Metode Formal yang merupakan teknik untuk membangun model secara sistematis dari suatu model yang yang kompleks akan digunakan pada penelitian kali ini, selain itu metode formal juga dapat memvalidasi spesifikasi secara independen, dengan demikian akan dapat menyelesaikan kesalahan sejak awal pengembangan EA. Dalam kajian ini menggunakan kualitas model validity atau validasi bisnis arsitektur bisnis menggunakan metode formal Petri net [9].

\section{METODE}

Tahapan yang dilakukan dalam melakukan validasi terhadap rancangan bisnis arsitektur seperti terlihat pada Gambar 1.

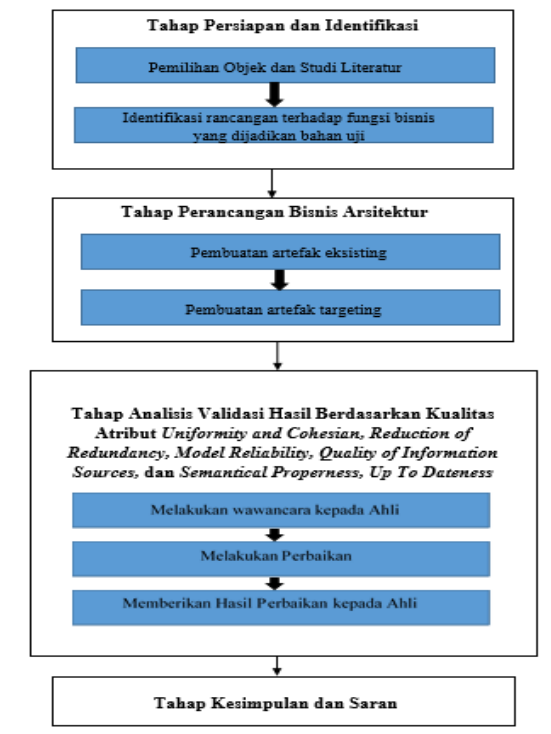

Gambar 1. Sistematika Penelitian
Tahap pertama pada sistematika penelitian ini merupakan tahap persiapan dan identifikasi. Hal pertama yang dilakukan ialah studi literatur mengenai pentingnya validasi dalam menentukan kesuksesan rancangan Enterprise Architecture serta dari sisi kelebihan dan kekurangan dilakukannya, sehingga dapat mendukung kesuksesan dari rancangan arsitektur bisnis. Berikutnya, menentukan metode yang digunakan serta bahasa pemodelan yang digunakan sehingga mendukung proses transformasi yang baik. Hal kedua yang dilakukan ialah mengumpulkan data - data pendukung seperti dokumentasi rancangan EA dan identifikasi terkait dokumentasi rancangan EA tersebut. Dan hal yang terakhir yang dilakukan pada tahap inisiasi yaitu memilih proses bisnis pada fungsi yang ada di perusahaan tepatnya pada sektor manufaktur yang dapat dijadikan sebagai objek penelitian.

Pada tahap perancangan bisnis arsitektur, ertefak eksisting di sebuah fungsi pada suatu perusahaan dibuat. artefak dibuat berdasarkan keadaan eksisting fungsi yang sudah dipilih pada perusahaan. Setelah artefak eksisting berhasil dibuat, perancangan selanjutnya membuat artefak targeting yang ada pada fase bisnis arsitektur pada fungsi marketing and sales sesuai dengan kebutuhan perusahaan saat itu.

Tahap analisis validasi hasil berdasarkan kualitas atribut uniformity and cohesion, reduction of redundancy, model reliability, quality of information sources, semantical properness, dan up to dateness merupakan tahap utama dalam penelitian kali ini. Pada tahap inilah akan melakukan validasi pada artefak yang telah di desain sebelumnya berdasarkan kualitas atribut dari quality principle validitas yang sudah disebutkan diatas. Keenam kualitas atribut tersebut 
dilakukan dengan cara melakukan wawancara dengan ahli yaitu mengajukan pertanyaan dengan berbagai metric type seperti qualitative, quantitative, dan Yes/No untuk mendapatkan validitas terkait dengan artefak yang telah di desain pada fase bisnis arsitektur.

Pada tahap penelitian kesimpulan dan saran, setelah melakukan analisis akan merangkum yang telah diteliti sehingga dapat memberikan kesimpulan mengenai metode yang digunakan terhadap perusahaan di sektor manufaktur serta dapat menjadi landasan baru dalam penelitian berikutnya mengenai metode validasi dengan petri net, sehingga dapat memberikan saran sebagai bahan pertimbangan dalam merancang arsitektur sistem informasi khususnya pada pemodelan artefak pada bisnis arsitektur sehingga dapat sesuai dengan kualitas prinsip beserta kualitas atributnya.

\section{HASIL DAN PEMBAHASAN}

Tabel 1 merupakan daftar pertanyaan dari masing - masing atribut turunan dari principle quality validitas. Pertanyaan inilah yang dibuat untuk nantinya dapat diajukan pada ahli EA. dan hasil dari pertanyaan yang diajukan kepada ahli dapat dijadikan rujukan untuk melakukan perbaikan atau penambahan informasi didalam artefak yang dirasa kurang lengkap.

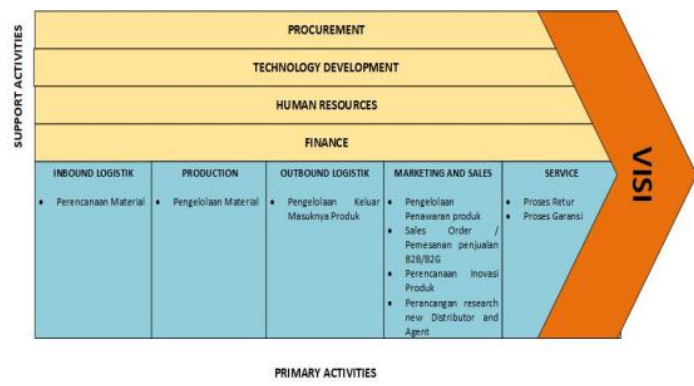

Gambar 2. Value Chain

Pada Gambar 2 menjelaskan tentang aktivitas utama pada perusahaan pada masing - masing fungsi seperti Inbound Logistik, Production, Outbound Logistik, Marekting and Sales, dan Service. Dan juga menjelaskan tentang mana saja aktivitas pendukung perusahaan.

Tabel 1. Daftar Pertanyaan Ahli EA

\begin{tabular}{|c|c|c|c|c|}
\hline $\begin{array}{l}\text { Prinsip } \\
\text { Kualitas }\end{array}$ & Atribut Kualitas & Penilaian Atribut & Type Matric & Sumber \\
\hline \multirow{7}{*}{ Validity } & $\begin{array}{l}\text { Uniformity and } \\
\text { Cohesion }\end{array}$ & $\begin{array}{l}\text { Apakah Model EA dirancang berdasarkan } \\
\text { framework EA dan metode EA? }\end{array}$ & Yes/No & $\begin{array}{c}{[10],[11],} \\
{[12]}\end{array}$ \\
\hline & $\begin{array}{l}\text { Reduction of } \\
\text { Redundancy }\end{array}$ & $\begin{array}{l}\text { Mengidentifikasi duplikat implisit yang terjadi } \\
\text { pada model EA }\end{array}$ & Qualitative & [13] \\
\hline & Model Realibility & $\begin{array}{l}\text { Apakah model EA dapat berfungsi sesuai yang } \\
\text { diharapkan? }\end{array}$ & Qualitative & {$[10],[12]$} \\
\hline & $\begin{array}{c}\text { Quality of } \\
\text { Information } \\
\text { System }\end{array}$ & $\begin{array}{c}\text { Dapatkah sumber informasi yang ada } \\
\text { digunakan oleh model EA dianggap sudah } \\
\text { tepat? }\end{array}$ & Qualitative & [11] \\
\hline & $\begin{array}{l}\text { Semantical } \\
\text { Properness }\end{array}$ & $\begin{array}{l}\text { Apakah model EA sudah dapat berguna untuk } \\
\text { memetakan setiap fungsi di perusahaan? }\end{array}$ & Qualitative & [14] \\
\hline & Up To Dateness & $\begin{array}{c}\text { Apakah model EA dapat merepresentasikan } \\
\text { kondisi saat ini? }\end{array}$ & Quantitative & [11] \\
\hline & $\begin{array}{l}\text { Syntactical } \\
\text { Properness }\end{array}$ & Validasi terhadap Sintaks bahasa & Tools & {$[10],[14]$} \\
\hline
\end{tabular}



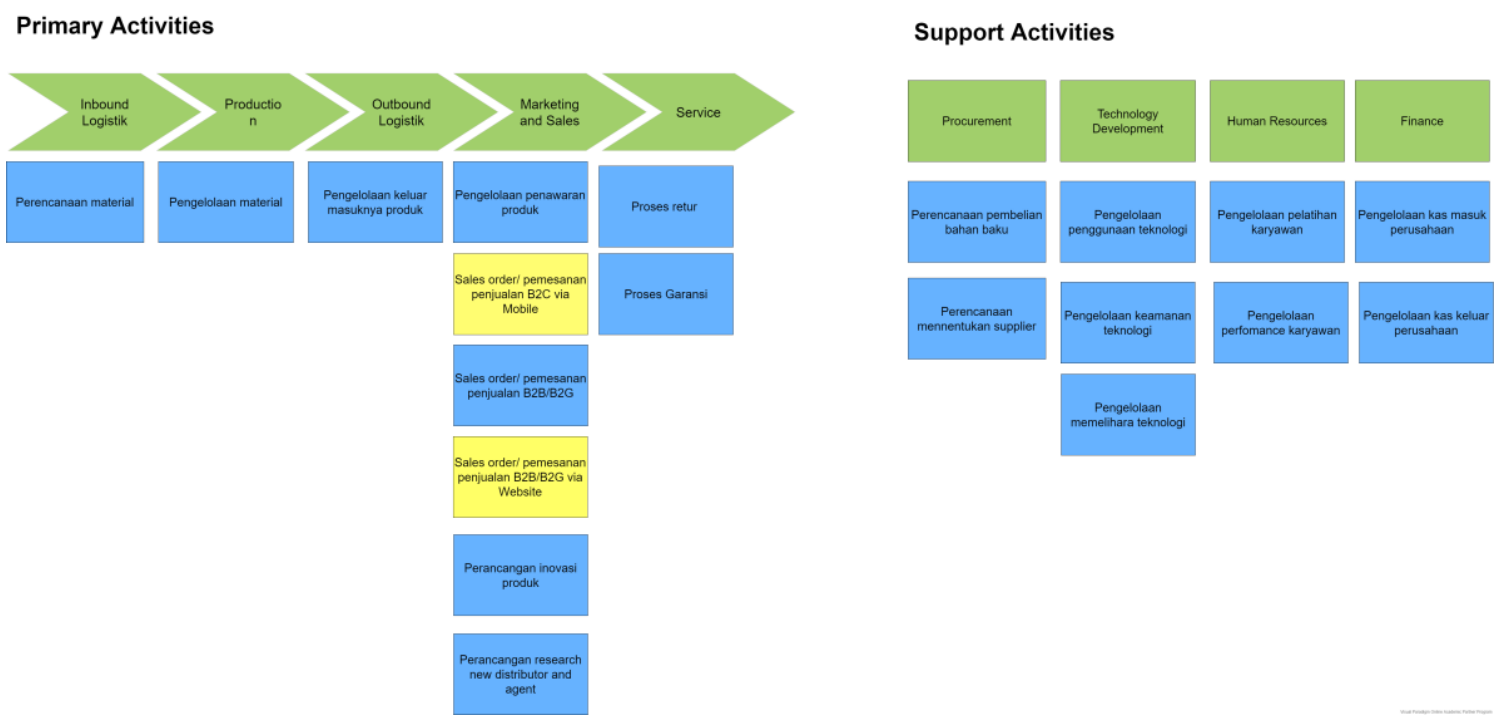

Gambar 3. Functional Decomposition Diagram

Pada Gambar 3 menjelaskan service atau layanan yang ditawarkan pada masing - masing fungsi yang ada pada aktivitas utama maupun aktivitas pendukung perusahaan.

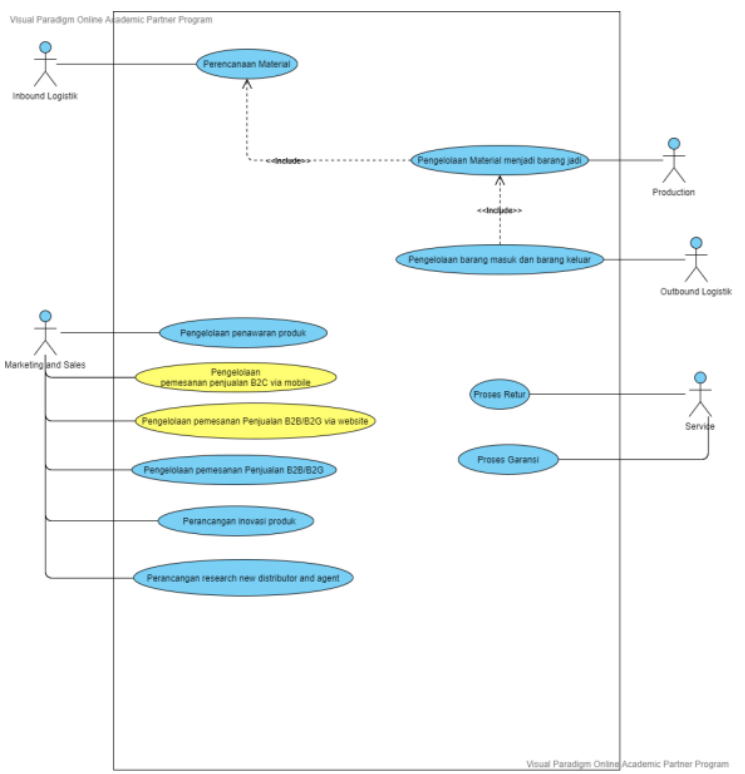

Gambar 4. Use-Case Diagram

Pada Gambar 4 menjelaskan hubungan Dri satu use-case ataupun sistem yang ada pada perusahaan disetiap fungsi yang ada.
Setelah mendapatkan jawaban dari ahli EA seperti yang terlihat pada Tabel 2 terkait pertanyaan yang sudah diajukan dari masing - masing atribut turunan dari quality principle validitas, maka dapat disimpulkan bahwa pada atribut kualitas reduction of redundancy belum ada flow diagram yang mampu menjelaskan alur pertukaran data dari suatu fungsi ke fungsi lain maupun dari suatu aktivitas ke aktivitas lain, Seperti yang ditunjukkan pada Gambar 5.

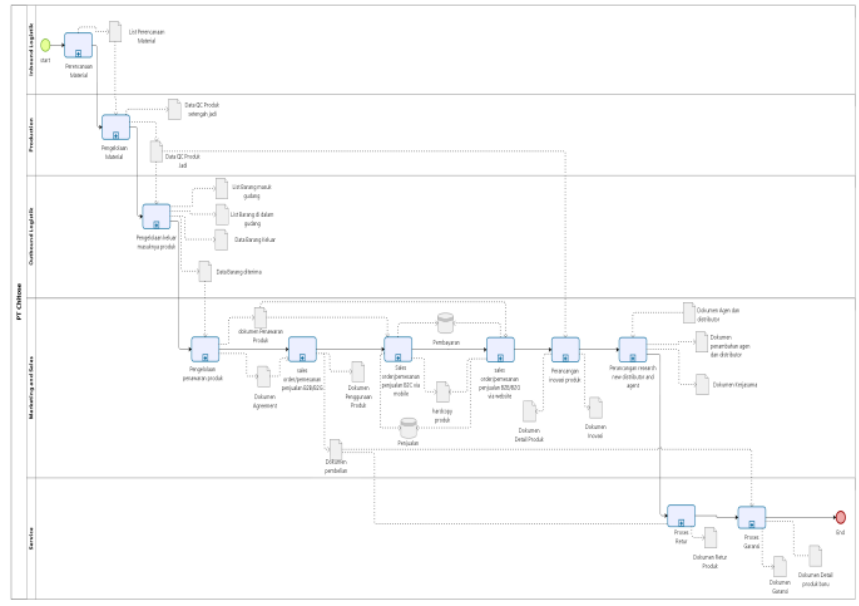

Gambar 5. Flow Diagram 
JURTEKSI (Jurnal Teknologi dan Sistem Informasi)

Vol. VII No. 2, April 2021, hlm. 173 - 180

DOI: https://doi.org/10.33330/jurteksi.v7i2.1009

Available online at http://jurnal.stmikroyal.ac.id/index.php/jurteksi

Selain itu, dilihat pada Tabel 2 atribut kualitas model reability para ahli juga setuju bahwa perlu pembuatan roadmap pada fase bisnis arsitektur yang digunakan untuk memandu menyelesaikan proyek yang akan dilakukan terlebih dahulu hingga proyek tersebut mencapai target perusahaan.

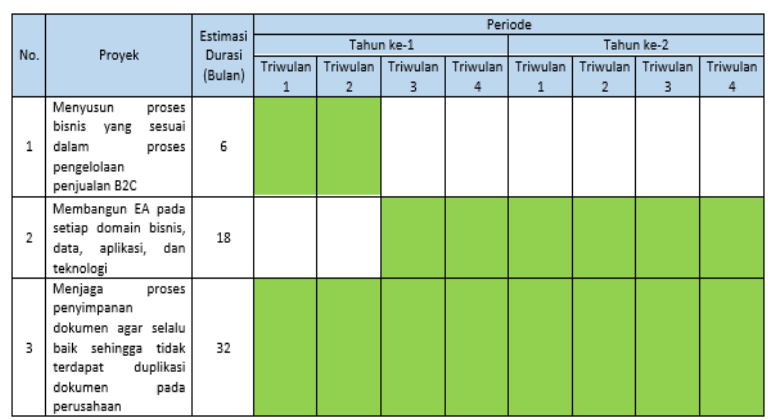

Gambar 6. Roadmap
ISSN 2407-1811 (Print)

ISSN 2550-0201 (Online)

Tabel 2. Hasil Jawaban Ahli EA

\begin{tabular}{|c|c|c|c|c|}
\hline $\begin{array}{l}\text { Prinsip } \\
\text { Kualitas }\end{array}$ & $\begin{array}{l}\text { Atribut } \\
\text { Kualitas }\end{array}$ & Penilaian Atribut & Type Matric & Kesimpulan Jawaban Ahli \\
\hline \multirow{7}{*}{ Validity } & $\begin{array}{l}\text { Uniformity and } \\
\text { Cohesion }\end{array}$ & $\begin{array}{c}\text { Apakah Model EA } \\
\text { dirancang berdasarkan } \\
\text { framework EA dan } \\
\text { metode EA? }\end{array}$ & Yes/No & $\mathrm{Ya}$ \\
\hline & $\begin{array}{l}\text { Reduction of } \\
\text { Redundancy }\end{array}$ & $\begin{array}{l}\text { Mengidentifikasi duplikat } \\
\text { implisit yang terjadi pada } \\
\text { model EA }\end{array}$ & Qualitative & $\begin{array}{l}\text { Tidak terdapat redundansi sistem dilihat } \\
\text { dari seluruh artefak, hanya saja kurang } \\
\text { menjelaskan alur data dalam bentuk flow } \\
\text { dagram pada sistem dengan jelas }\end{array}$ \\
\hline & $\begin{array}{l}\text { Model Reali- } \\
\text { bility }\end{array}$ & $\begin{array}{l}\text { Apakah model EA dapat } \\
\text { berfungsi sesuai yang } \\
\text { diharapkan? }\end{array}$ & Qualitative & $\begin{array}{l}\text { Dapat, karena artefak yang didesain telah } \\
\text { mengikuti visi, misi, dan goal } \\
\text { perusahaan. Tetapi belum adanya } \\
\text { roadmap agar dapat diimplementasikan }\end{array}$ \\
\hline & $\begin{array}{l}\text { Quality of } \\
\text { Information } \\
\text { System }\end{array}$ & $\begin{array}{l}\text { Dapatkah sumber } \\
\text { informasi yang ada } \\
\text { digunakan oleh model EA } \\
\text { dianggap sudah tepat? }\end{array}$ & Qualitative & $\begin{array}{l}\text { Sudah dianggap tepat, karena didalam } \\
\text { value chain terdapat aktivitas utama dan } \\
\text { aktivitas pendukung dan terdapat } \\
\text { informasi lainnya berdasarkan eksisting } \\
\text { perusahaan }\end{array}$ \\
\hline & $\begin{array}{l}\text { Semantical } \\
\text { Properness }\end{array}$ & $\begin{array}{l}\text { Apakah model EA sudah } \\
\text { dapat berguna untuk } \\
\text { memetakan setiap fungsi } \\
\text { di perusahaan? }\end{array}$ & Qualitative & $\begin{array}{l}\text { Sudah, karena model EA yang dedesain } \\
\text { sudah sesuai dengan kerangka kerja yang } \\
\text { digunakan dan artefak telah } \\
\text { menyesuaikan kebutuhan perusahaan }\end{array}$ \\
\hline & $\begin{array}{c}\text { Up To } \\
\text { Dateness }\end{array}$ & $\begin{array}{l}\text { Apakah model EA dapat } \\
\text { merepresentasikan kondi- } \\
\text { si saat ini ? }\end{array}$ & Quantitative & $\begin{array}{l}\text { Dapat, dilihat berdasarkan Date of Last } \\
\text { Change : } 2018 \text { dengan frequency } \\
\text { sebanyak : } 4 \text { kali }\end{array}$ \\
\hline & $\begin{array}{l}\text { Syntactical } \\
\text { Properness }\end{array}$ & $\begin{array}{c}\text { Validasi terhadap Sintaks } \\
\text { bahasa }\end{array}$ & Tools & $\begin{array}{l}\text { Terpenuhinya setiap properti yang ada } \\
\text { pada structural analysis seperti free- } \\
\text { choice, s-component, liveness, } \\
\text { boundedness, workflow net, initial } \\
\text { marking, wrongly used operator yang } \\
\text { terdapat pada tools }\end{array}$ \\
\hline
\end{tabular}


Dapat dilihat pada Tabel 2 bahwa artefak yang dibangun sudah sesuai dengan kebutuhan perusahaan maupun kondisi eksisting perusahaan, hanya saja pada atribut kualitas reduction of redundancy dan model reability harus menambahkan flow diagram seperti pada Gambar 5 dan juga menambahkan roadmap seperti Gambar 2.

\section{SIMPULAN}

Berdasarkan hasil wawancara dengan mengajukan pertanyaan kepada ahli EA sesuai dari masing - masing atribut turunan yang terdapat pada quality principle validitas terkait perancangan Business Architecture fungsi Marketing and Sales pada Perusahaan Manufacturing khususnya pada pemodelan bisnis ataupun artefak didalamnya, terdapat beberapa penambahan yang harus dibuat seperti flow diagram yang bertujuan untuk menjelaskan alur pertukaran data dari suatu fungsi ke fungsi lain maupun dari suatu aktivitas ke aktivitas lain. Serta pembuatan roadmap pada fase bisnis arsitektur yang digunakan untuk memandu menyelesaikan proyek yang akan dilakukan terlebih dahulu hingga proyek tersebut mencapai target perusahaan.

\section{DAFTAR PUSTAKA}

[1] T. Tamm, P. B. Seddon, G. Shanks, and P. Reynolds, "How does enterprise architecture add value to organisations?," Commun. Assoc. Inf. Syst., vol. 28, no. 1, pp. 141-168, 2011, doi: 10.17705/1cais.02810.

[2] N. A. A. Bakar, S. Harihodin, and N. Kama, "Enterprise architecture implementation model: Measurement from experts and practitioner perspectives," Colloq. Inf. Sci. Technol. Cist, vol. 0, pp. 1-6, 2016, doi: 10.1109/CIST.2016.7804849.

[3] Z. R. Putra, A. Rachmadi, and N. Y. Setiawan, "Evaluasi dan Pemodelan Proses Bisnis Menggunakan Business Process Management Notation dan Quality Evaluation Framework ( QEF ) Pada Perusahaan Gumcode Indonesia," vol. 3, no. 1, pp. 1053-1061, 2019.

[4] L. Retnawati, "Perancangan Enterprise Architecture Menggunakan TOGAF di Universitas ABC," J. IPTEK, vol. 22, no. 1, p. 13, 2018, doi: 10.31284/j.iptek.2018.v22i1.221.

[5] A. A. Al-ghamdi and F. Saleem, "The Impact of ICT Applications in the Development of Business Architecture of Enterprises," Int. J. Manag. Stud. Res., vol. 4, no. 4, pp. 22-28, 2016, doi: 10.20431/2349-0349.0404005.

[6] I. Moreno-Montes De Oca, M. Snoeck, H. A. Reijers, and A. Rodríguez-Morffi, "A systematic literature review of studies on business process modeling quality," Inf. Softw. Technol., vol. 58, pp. 187-205, 2015, doi: 10.1016/j.infsof.2014.07.011.

[7] F. Timm, S. Hacks, F. Thiede, and D. Hintzpeter, "Towards a quality framework for enterprise architecture models," CEUR Workshop Proc., vol. 2017, no. November, pp. 14-21, 2017.

[8] A. Queralt and E. Teniente, "Verification and validation of UML conceptual schemas with OCL constraints," ACM Trans. 
Softw. Eng. Methodol., vol. 21, no. 2, 2012, doi: $10.1145 / 2089116.2089123$.

[9] K. M. Van Hee, N. Sidorova, and J. M. Van Der Werf, "Business process modeling using Petri nets," Lect. Notes Comput. Sci. (including Subser. Lect. Notes Artif. Intell. Lect. Notes Bioinformatics), vol. 7480 LNCS, no. 257129, pp. 116-161, 2013, doi: 10.1007/978-3-642-381430 4.

[10] Á. Rocha, A. M. Correia, F. B. Tan, and K. A. Stroetmann, "New Perspectives in Information Systems and Technologies, Volume 2," Adv. Intell. Syst. Comput., vol. 276 VOLUME, pp. 63-71, 2014, doi: 10.1007/978-3319-05948-8.

[11] E. Niemi and S. Pekkola, "Enterprise Architecture quality attributes: A case study," Proc. Annu. Hawaii Int. Conf. Syst. Sci., pp. 3878-3887, 2013, doi:
10.1109/HICSS.2013.201.

[12] R. Khayami, "Qualitative characteristics of enterprise architecture," Procedia Comput. Sci., vol. 3, pp. 1277-1282, 2011, doi: 10.1016/j.procs.2011.01.004.

[13] N. Lim, T. G. Lee, and S. G. Park, "A comparative analysis of enterprise architecture frameworks based on EA quality attributes," 10th ACIS Conf. Softw. Eng. Artif. Intell. Netw. Parallel/Distributed Comput. SNPD 2009, conjunction with IWEA 2009 WEACR 2009, pp. 283-288, 2009, doi: 10.1109/SNPD.2009.97.

[14] C. Spence and V. Michell, "Experiences of tool-based enterprise modelling as part of architectural change management," BMSD 2015 - Proc. 5th Int. Symp. Bus. Model. Softw. Des., no. January, pp. 255-260, 2015, doi: $10.5220 / 0005887902550260$. 